\title{
Interactive comment on "Determinants of thermal regime influence of small dams" by André Chandesris et al.
}

\section{André Chandesris et al.}

andre.chandesris@irstea.fr

Received and published: 15 July 2019

\section{Dear Editor and Referees,}

Thank you for the quality of your proofreading and comments; they have greatly improved the manuscript. We also appreciate your interest in the subject matter, which we think is of critical importance to managers across France and the world who are dealing with issues of small dam removal and ecological integrity. We believe we have substantially addressed all of the outstanding comments and issues, and we look forward to your second review of the work. All of the referees remarked on the issue of data representativeness, so we will briefly discuss this issue here. Data scarcity (i.e., lack of data across years within sites) is a primary challenge for understanding thermal 
effects of small dams, and it is one of the primary reasons that we used a compiled dataset with data from field operators, which we bolstered with our own sampling. We acknowledge that using these two data sources may make reading and understanding a little more difficult, but we believe it enriches the analysis by increasing the number of time series and across-year examples, (though we agree this dataset is probably still insufficient to draw broad conclusions). Hence, we are aware of the issues with the dataset, and we have added text throughout to underscore this issue. However, we feel that the analysis and general results are valid and useful, regardless of data scarcity issues, which every study must deal with. Throughout the manuscript, we have made major revisions based on the referees comments and suggestions. The major changes are: - use of new statistical analysis methods to strengthen the robustness of the results, - improved consistency between points raised in the comments and proposed figures, - grammatical quality review: a final revision of English was done by a native speaker.

"General comments: The purpose of this study was to quantify the downstream impacts of different types of small dams on summer water temperature in lowland streams. The topic of this manuscript is of high importance, and the research is critically needed since water temperature could impact the structure of aquatic communities and the functioning of the aquatic ecosystem as stated by the authors. The data set on water temperature the authors have collected seems to be robust, and with quite enough number of sites. I personally appreciated the calibration process made for the instruments to insure reliable data. The discussion is quite thorough and insightful, but more focus on literature review (others work) rather than focusing on the discussion of the current work. I found that data analysis severely lacking, and the presentation of the results to be using individual sites as examples that are difficult to judge if they are really representative. Therefore, without adequate data analysis I felt that the conclusions were not well supported. The language used is not sufficiently comprehensible and needs to be improved before publication. Many other specific and technical comments can be found below."

Printer-friendly version

Discussion paper
Interactive comment 
Response: We have taken all these comments into account and paid particular attention to the statistical analysis of the data to support our conclusions.

Specific comments "1. P5, L159: Why authors calculate median differences and not mean? Please justifying why this metric instead of means."

Response: We prefer to work with seasonal variables that are not affected by exceptional one-time weather events.

To avoid any confusion, we eliminate any reference to daily mean temperature And we propose to modify the section 2.4 Data analysis (I 156 à 159)

Previous text: L156 to 159 To determine if the dams alter the temperature regime, the minimum, average and maximum temperatures and amplitudes were calculated for each full day recorded, and the median values were recorded for the period. The calculations of daily differences of maximum and minimum water temperatures were performed for each pair of upstream/downstream records, and the median of these differences over the recording period was calculated.

\section{Replaced by}

To characterize the influence of dams on stream thermal regimes we first calculated three variables: daily difference between upstream and downstream temperature 1) maximums, 2) minimums, and 3) ranges for each site and year. (..). With these data, we then conducted the following analyses: 1 . Median summer differences in maximum, minimum, and range between upstream and downstream (median is used instead of mean to characterize a season in order to limit the effect of a specific weather event), 2....

"2. Section 3.5: What is the scientific method used for group clustering?"

Fixed We add description of the statistical method used

Previous text: L 164 Finally, we propose a classification of the observed thermal be- 
havior in 3 groups, based on differences between upstream and downstream dam daily maximum temperature, daily minimum temperature and daily amplitudes.

Replaced by 2.5 Site typology analysis We observed different thermal regimes in our data and wanted to classify them. To do so, we carried out a hierarchical cluster analysis using Euclidian dissimilarities matrix according to the Ward's method (1963) using daily dataset $(n=807)$ of upstream/downstream differences between maximum and minimum temperatures obtained over all time-series. We forced the classification to integrate the different time-series effect by adding a complete disjunctive table differentiating each time-series to the data set. This procedure makes it possible to group the data first by time-series, then in a second step to differentiate them from each other (i.e., to differentiate site thermal regimes).

Previous text: L 204 to 2173.5 Site typology based on summer thermal regime The median values of the daily temperature variables calculated over summer (from 01/07 to $01 / 09$ ) permit distinguishing two major types of response to the presence of a small dam (Table 3). A first group $(A)$ is characterised by: - a median of the differences upstream/downstream of the maximum daily temperatures lower than $0.5^{\circ} \mathrm{C}$; - a median of the differences upstream/downstream of the minimum daily temperatures between +0.4 and $1.3^{\circ} \mathrm{C}$; - a median of the differences in daily amplitudes lower than $-0.2^{\circ} \mathrm{C}$. A second group $(\mathrm{B})$ is characterised by: - a median of the differences upstream/downstream of the maximum daily temperatures higher than $0.5^{\circ} \mathrm{C}$; - medians of the differences upstream/downstream of the maximum and minimum daily temperatures in the same order of amplitude. In addition two subgroups can be distinguished: subgroup (B2) with medians of upstream/downstream differences of daily maximum and minimum temperatures higher than $1^{\circ} \mathrm{C}$, i.e. net warming between upstream and downstream, and subgroup (B1) with values ranging from $0.3-0.8^{\circ} \mathrm{C}$.

Printer-friendly version

Replaced by 3.5 Site typology The hierarchical cluster analysis applied on the values of the daily temperature variable differences over summer (from 1 July to 31 August) distinguished three groups: - a first group (A) characterized by: - a median of the dif- 
ferences upstream/downstream of the maximum daily temperatures less than $0.5^{\circ} \mathrm{C}$; - a median of the differences upstream/downstream of the minimum daily temperatures between $+0.4-1.3^{\circ} \mathrm{C}$; - a median of the differences in daily amplitudes less than $-0.2^{\circ} \mathrm{C}$. - a second group (B1) characterized by: - a median of the differences upstream/downstream of the maximum daily temperatures ranging from $+0.6-1.2{ }^{\circ} \mathrm{C}$; - a median of the differences upstream/downstream of the minimum daily temperatures between $+0.3-1.1^{\circ} \mathrm{C}$. - a third group (B2) is characterized by medians of upstream/downstream differences of daily maximum and minimum temperatures both higher than $1.2^{\circ} \mathrm{C}$ (i.e., net warming between upstream and downstream)

Figure 6 changed

"3. Section 3.7: the results presented in this section are unclear and the purpose of presenting such results is unclear as well. I found it very hard to link this section with the discussion section. This would be easy for the reader if the results and discussion section were compiled in one section."

Fixed Fully rewritten

Previous text L234 to 239 3.7 Focus on temperature pattern in short period of time Looking more specifically on a short period of time (three consecutive days), differences in the diurnal variation of the 235 temperature of the river upstream and downstream of the dam shows that for the first group $A$, the maximum water temperatures upstream and downstream are close, while the minimum temperature downstream does not return to that of upstream (Fig. 9A). In the second group B the water temperature difference between upstream and downstream are more important and remain persistent during all the day period (Fig. 9B).

Replaced by 3.7 Focus on temperature pattern in intra-daily temperature variations To further illustrate the different thermal regime effects from our typology analysis, we compare intra-daily temperature variations for a three-day time series in group $A$ (small thermal effect) with group B (large thermal effect; Fig. 9): - In the example of group

Printer-friendly version

Discussion paper 
A (Fig. 9A), the downstream temperature is generally warmer than the upstream temperature (observed difference of $1^{\circ} \mathrm{C}$ warmer) except for a few hours during the three day sample observation period. The biological benchmark of $22^{\circ} \mathrm{C}$ is exceeded both upstream and downstream during the day of August 20. The rest of the time, temperatures are below this threshold. From a biological point of view, the duration above the thermal threshold is short, preceded and followed by more favorable temperatures (i.e., the remission period). - In the example of group B (Fig. 9B), the downstream temperature is systematically higher than that of the upstream, with a temperature difference varying between $+0.8-2 \cdot 4^{\circ} \mathrm{C}$. The $22^{\circ} \mathrm{C}$ threshold is exceeded downstream for a cumulative $42 \mathrm{~h}$ over the three-day period. August 15 and 16 have downstream temperatures that rarely go below $22^{\circ} \mathrm{C}$, leaving no time for thermal remission (return to a temperature that is better tolerated physiologically by fish). At the same time, the upstream part of the stream is maintained at daily temperatures not exceeding this threshold. - Additionally; differences in the diurnal temperature variation upstream and downstream of the dam shows that for group A, the maximum water temperatures are close, whereas the minimum temperature downstream does not return to that of upstream (Fig. 9A). In group $B$ the water temperature difference between upstream and downstream are persistent throughout the diurnal cycle (Fig. 9B). For all sites, by studying the average daily duration with a temperature exceeding $22^{\circ} \mathrm{C}$ continuously, we can see (Fig. 10): - downstream durations are always greater than or equal to that of the upstream durations, regardless of site typology, - the largest upstream/downstream differences occur in the group B2 group, - group A is generally not affected by an upstream/downstream increase, except for two sites which exhibit a two hour increase.

A new sentence is added in 2.4 data analysis To assess the potential biological importance of dam thermal effects, we also calculated 1) the number of days that water temperatures were greater than $22^{\circ} \mathrm{C}$, and 2) the mean of the maximum daily duration (in hours) where water temperature was greater than $22^{\circ} \mathrm{C}$. We chose $22^{\circ} \mathrm{C}$ as an illustrative threshold known to be a thermal stress benchmark value for salmonids (Elliott and Elliot, 2010; Ojanguren et al., 2001).

Printer-friendly version

Discussion paper
Interactive comment 
$\mathrm{L} 162$ (iv) the dam thermal effect considering an arbitrary threshold of $22{ }^{\circ} \mathrm{C}$, with a calculation of the number of days above this threshold.

Replaced by 4 . calculation of the number of days above the biological $22^{\circ} \mathrm{C}$ threshold, and 5. calculation of the average maximum daily duration (in hours) above the biological $22^{\circ} \mathrm{C}$ threshold.

$\mathrm{L} 344$ to 346 placed in data analysis $\mathrm{L} 164$ We have chosen temperature $>22^{\circ} \mathrm{C}$ as an illustrative threshold known to be a thermal stress benchmark value for salmonids especially for brown trout, Salmo trutta (Elliott and Elliot, 2010: upper critical incipient lethal temperature for alevins considered as a very sensitive stage; Ojanguren et al., 2001: general activity of brown trout juvenile).

Previous text: $\mathrm{L} 344$ to $346 \mathrm{We}$ have chosen temperature $>22^{\circ} \mathrm{C}$ as an illustrative threshold known to be a thermal stress benchmark value for salmonids especially for brown trout, Salmo trutta (Elliott and Elliot, 2010: upper critical incipient lethal temperature for alevins considered as a very sensitive stage; Ojanguren et al., 2001: general activity of brown trout juvenile).

Replaced by In this study, we used a temperature of $22^{\circ} \mathrm{C}$ as an illustrative threshold known to be a thermal stress benchmark value for salmonids, especially for brown trout, Salmo trutta (Elliott and Elliot, 2010: upper critical incipient lethal temperature for juveniles, which is considered a very sensitive stage; Ojanguren et al., 2001: general activity of brown trout juvenile). In addition; this threshold is known to be important for the life cycle of aquatic invertebrates (Ward, 1976; Brittain and Salveit, 1989).

$\mathrm{L} 242$ For example, for the maximum daily temperature threshold of $22^{\circ} \mathrm{C}$ (arbitrary value),

\section{Replaced by}

For example, for the maximum daily temperature threshold of $22^{\circ} \mathrm{C}$,

"4. P7, section 3.8: Authors mention that the maximum daily temperature threshold 
of $22{ }^{\circ} \mathrm{C}$ is arbitrary value. While later in the discussion, the authors indicate that the choice of a $22^{\circ} \mathrm{C}$ is actually not arbitrary. I suggest that authors delete the word arbitrary and explain the basis of this threshold choice."

Fixed Arbitrary is suppressed See above

"5. P8, L255: the authors mention warmer, drier, colder and wetter years. Please discuss how these classifications are made?"

\section{Fixed Clarification by adding a sentence $L 153$}

The summer climatic characteristics for our analysis period are compared with the normal values produced by Meteo France (1981-2010).

"6. P18: Fig.4: what is the reason for comparing temperature of different sites (Dompierre and Neuf) in different years (e.g. 2010 and 2016)."

\section{Fixed}

Response: Figure 4 has been modified. We now use the same sites as in Figures 2 and 3 to make it easier to read. The purpose of the comparison is to illustrate the distribution of the differences in diff_Tmin and diff_Tmax between the two main types of thermal response. We follow the recommendation and propose a new set of figures (Fig.2 and Fig.4)

Previous text: $L 191$ to 194 The two dominant patterns can be illustrated by plotting the minimum and maximum temperature values at the site "Dompierre 2010" with a difference of order of $+1.5^{\circ} \mathrm{C}$ between the upstream and downstream of the site, comparing to "Neuf 2016", where these values are the same for minimum daily temperatures, or even slightly negative for the maximum temperatures (Fig. 4).

\section{Replaced by}

The two dominant patterns of temperature differences can be further illustrated by plotting the minimum and maximum temperature values at the site. For example, at 
"Dompierre 2010", we observed a consistent shift of approximately $+1.5^{\circ} \mathrm{C}$ (both maximum and minimum daily temperature) between the upstream and downstream of the dam (Fig. 4). In contrast, at "Fretaz 2014", this shift is dampened, and temperature values between upstream and downstream follow a 1:1 relationship (Fig. 4).

7. P19: Fig.3 caption: the authors state "time-series of water temperatures upstream (blue line) and downstream (red line) of the dams of Dompierre and Peroux, Veyle stream (2010 and 2015, two warm summer years, respectively $+1.1^{\circ} \mathrm{C}$ and $2^{\circ} \mathrm{C}$, Table $2)$ ", but when looking back in table 2, I have seen that air temperature difference from normal in 2010 is very small $(+0.3)$ and NOT +1.1 . The $+1.1^{\circ} \mathrm{C}$ air temperature difference from normal is in the year 2009. Therefore, 2009 is almost four times warmer than 2010, hence one may expect the comparison between 2009 and 2015 instead of 2010 and 2015?"

Fixed Corrected legend and site changed Removal of "two warm summer years, respectively $+1.1^{\circ} \mathrm{C}$ and $2^{\circ} \mathrm{C}$, Table $2^{\prime \prime}$ in Fig.3 caption.

"8. P19: Fig.3: Since air temperature difference from normal in 2010 is very small (+ 0.3), why the difference between upstream and downstream water temperature at Dompierre dam is very high? This cannot be due to long residence time and average surface are in absence of warm condition, so what could be the reason/s?"

Response: The low deviation from normal indicates a summer temperature close to this normal. The figure shows that the amount of heat supplied to the stream during a "normal" summer is sufficient to vary the temperature between the upstream and downstream of the dam taking into account the long residence time (8.4 days) and the surface of the water body $\left(10900 \mathrm{~m}^{2}\right)$.

"9. It is insecurely to compare 2014 (cold and wet year) with 2015 (warm and dry year) for at least one site (e.g. Dompierre dam) to see the effect of air temperature."

The difference between the upstream and downstream of the dam does not appear to

Printer-friendly version

Discussion paper 
be solely related to air temperature, as shown in Figure 5. Unfortunately, we have no data available for the same site for these two years. We modify Figure 5 and the text as follows:

Previous text $L 200$ to 204 During the summer season, the differences in the daily mean temperatures upstream / downstream, are close or staggered during all the season. It is notable that the variability of the summer air temperature is much higher (range $17^{\circ} \mathrm{C}$ ) than stream temperature (range $7.5^{\circ} \mathrm{C}$ ) for these examples (Fig. 5), and that the daily water temperature is not well correlated to air temperature.

\section{Replaced by}

During the summer season, the upstream/downstream daily maximum water temperature differences are not well correlated with air temperature for the same periods. For example, a simple linear regression between daily maximum air temperature and daily maximum water temperature differences indicates that air temperature explains only $0.3 \%$ of the variability in upstream/downstream thermal regime shifts (Fig. 5).

Technical corrections: "1. P18: in Fig.2 caption, what is the word "respectively" refer to?"

Fixed Response: New figure with site Fretaz 2014 - 2016 (Fig.2) "respectively" is suppressed

2. $\mathrm{P} 1, \mathrm{~L} 18-19:$ "The mean increase of the minimum daily temperature was $1^{\circ} \mathrm{C}$, with $85 \%$ of the time-series showing an increase $>0.5{ }^{\circ} \mathrm{C}$ ", this sentence is not clear or grammatically incorrect. Fixed Previous text: L18 to 19 The mean increase of the minimum daily temperature was $1^{\circ} \mathrm{C}$, with $85 \%$ of the time-series showing an increase $>0.5^{\circ} \mathrm{C}$.

\section{Replaced by}

Across all time series, the mean increase of the minimum daily temperature was $1^{\circ} \mathrm{C}$, and for $85 \%$ of the sites the increase was higher than $0.5^{\circ} \mathrm{C}$. "3. P2, L63-64: "surface 
release reservoirs", should read "surface reservoirs' release"."

\section{Fixed}

"4. P5, L148-149: "in the main flow of the channel" should read "in the main flow channel"."

\section{Fixed}

"5. P5, L151: "method Dunham et al. (2005)." should read "method introduced by Dunham et al. (2005)"."

\section{Fixed}

"6. P5, L157: the authors state that "and the median values were recorded for the period", how do you record the median? It should read "calculated" instead." Fixed

"7. P6, L182: "Furthermore, the average temperature downstream of the structure was systematically higher or equivalent than that measured upstream" should read "Furthermore, the average temperature downstream of the structure was systematically equivalent or higher than that measured upstream"." Fixed

"8. These are limited examples and the paper contains more. All grammatical errors should be fixed before publication."

A final revision of English was done by a native speaker

We hope we have satisfactorily replied to your comments and issues, which we believe substantially increased the readability and understanding of this manuscript.

Best regards,

The Authors

Please also note the supplement to this comment:

Discussion paper https://www.hydrol-earth-syst-sci-discuss.net/hess-2019-136/hess-2019-136-AC3-

\section{C11}


supplement.pdf

Interactive comment on Hydrol. Earth Syst. Sci. Discuss., https://doi.org/10.5194/hess-2019136, 2019.

\section{HESSD}

Interactive

comment 
Interactive

comment

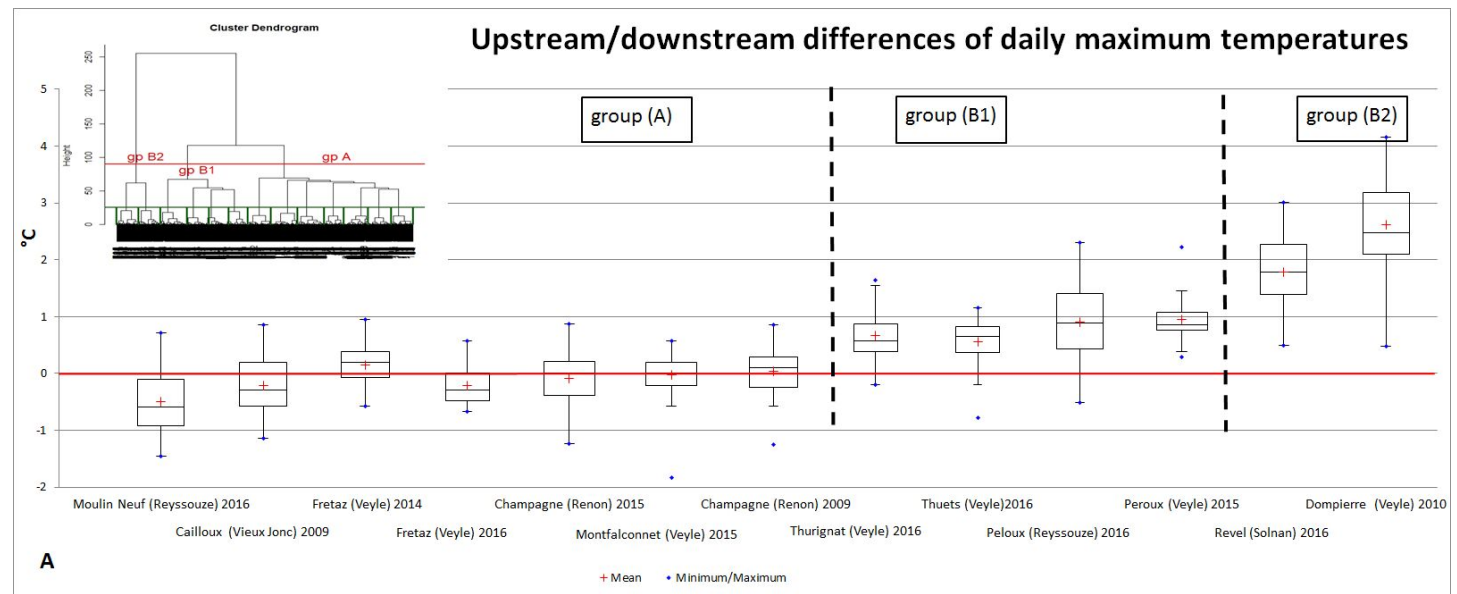

Fig. 1. Figure 6. Box-plot distribution (25\%- $75 \%$ ) of upstream/downstream differences of daily maximum $(A)$ and minimum $(B)$ temperatures for all the time-series studied. (Red lines: $0^{\circ} \mathrm{C}$ for daily maximum te 


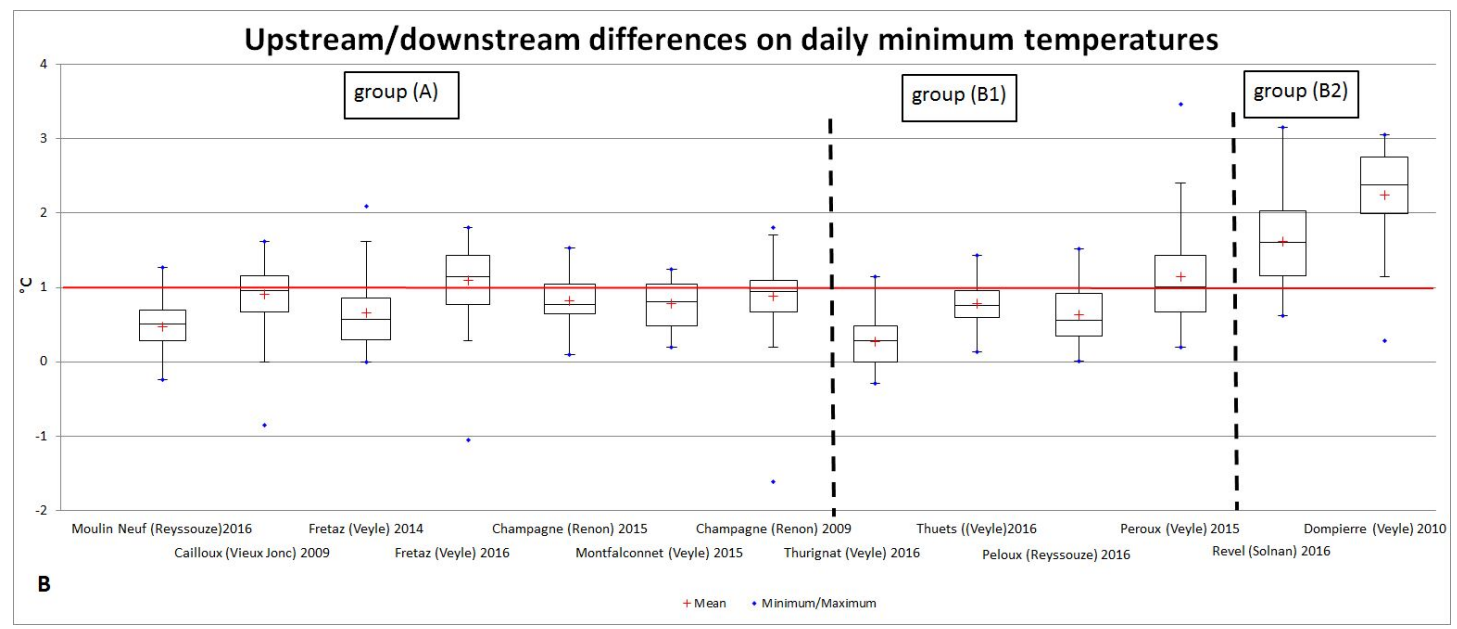

Interactive

comment

Fig. 2. Figure 6. Box-plot distribution (25\%- $75 \%)$ of upstream/downstream differences of daily maximum (A) and minimum (B) temperatures for all the time-series studied. (Red lines: $0^{\circ} \mathrm{C}$ for daily maximum te 


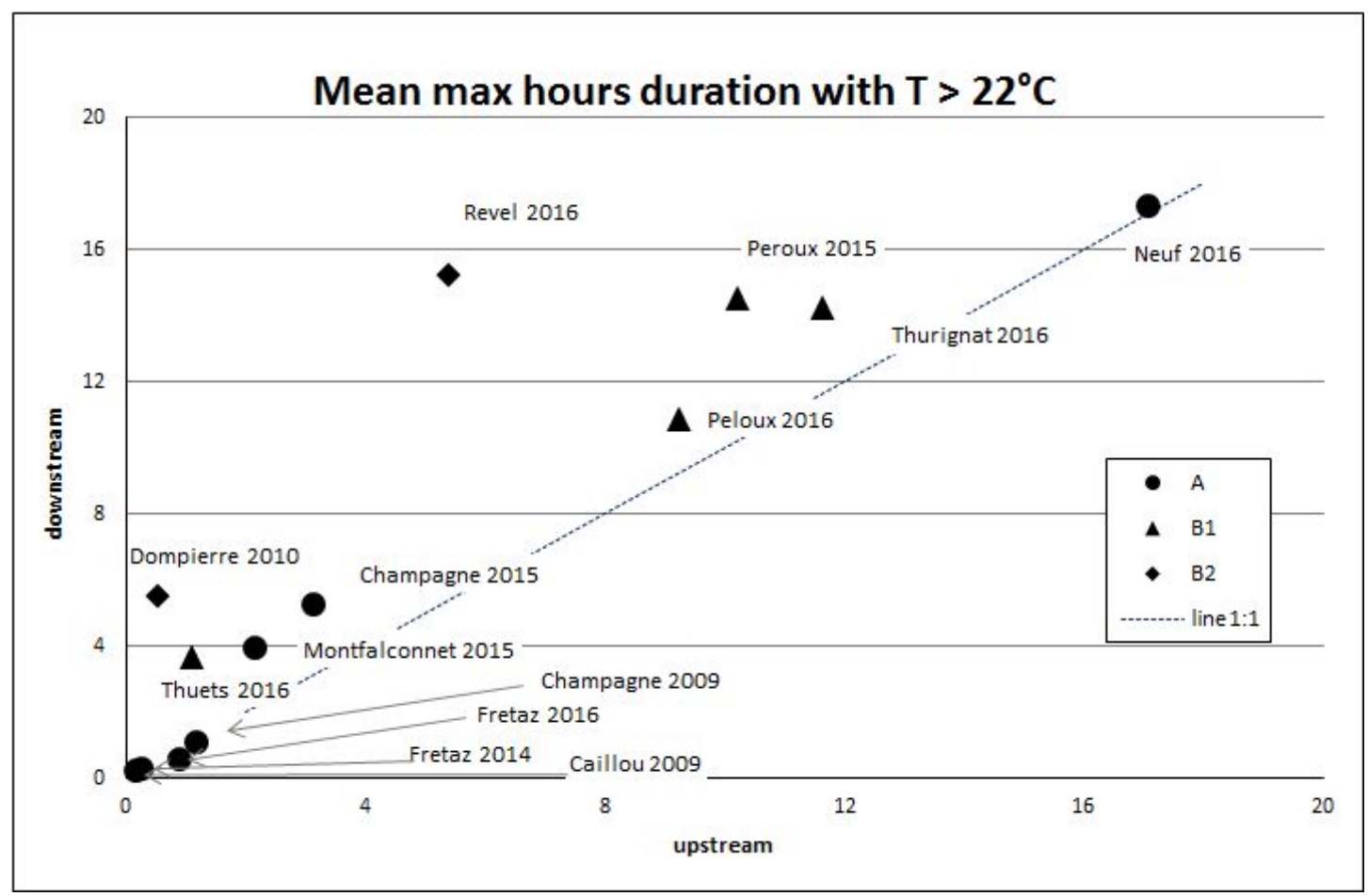

Interactive

comment

Fig. 3. Figure 10. Mean of the daily maximum duration with $\mathrm{T}$ above $22{ }^{\circ} \mathrm{C}$, upstream and downstream each site monitored in the study. A (circles), B1 (triangles), B2 (rhombus) are the groups of sites resulting 


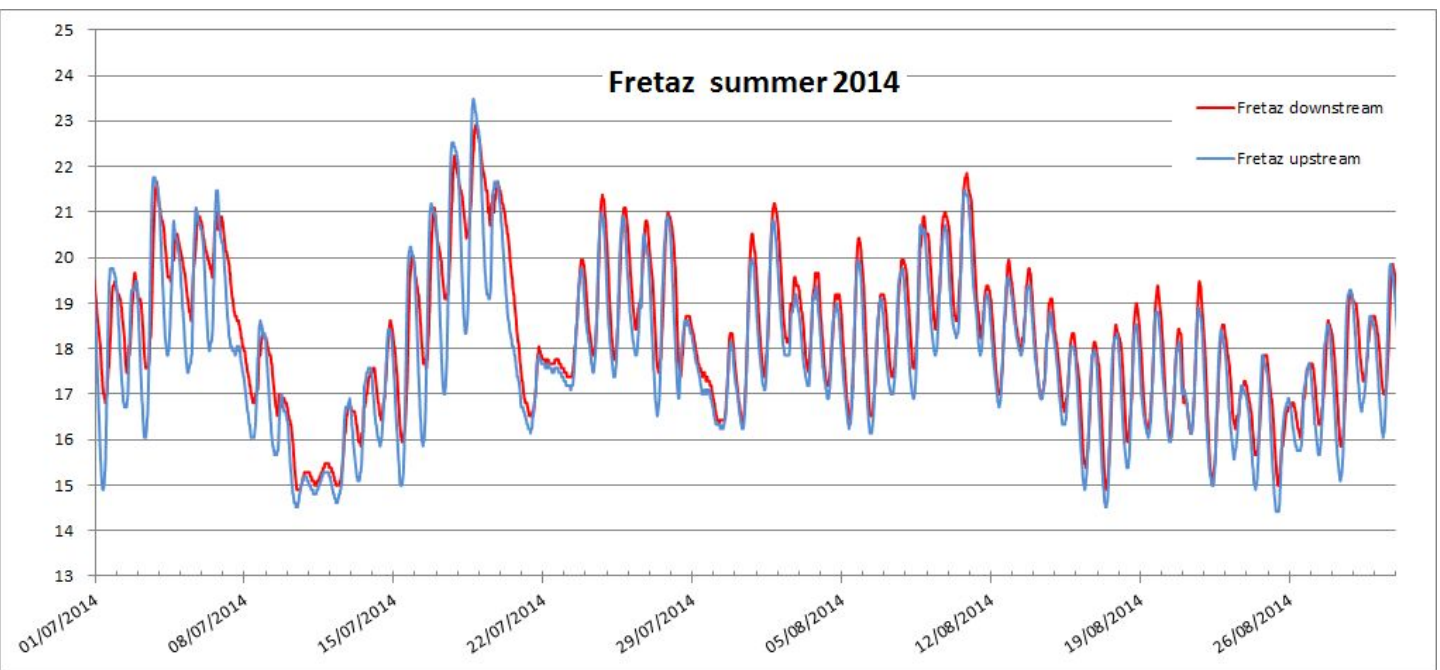

Fig. 4. Figure 2. Time-series of water temperature $\left({ }^{\circ} \mathrm{C}\right)$ upstream (blue) and downstream (red) of the dam Fretaz, Veyle stream, respectively in years 2014 and 2016.

Interactive

comment 
Interactive

comment

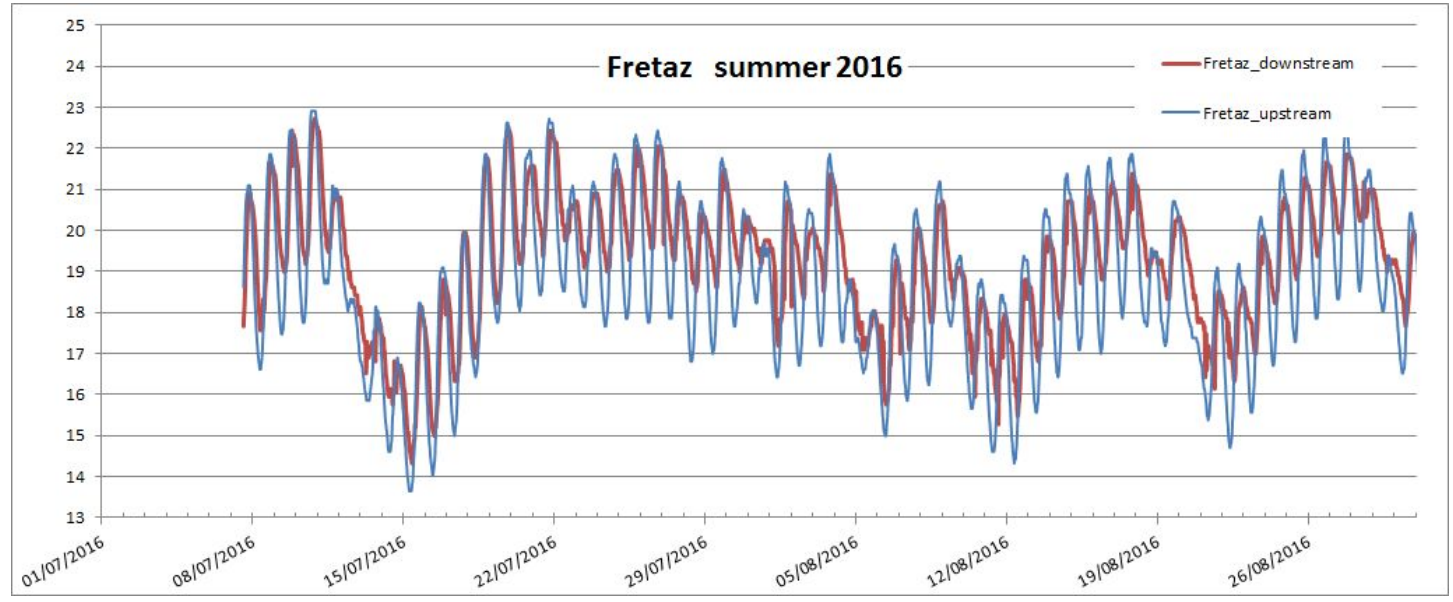

Fig. 5. Figure 2. Time-series of water temperature $\left({ }^{\circ} \mathrm{C}\right)$ upstream (blue) and downstream (red) of the dam Fretaz, Veyle stream, respectively in years 2014 and 2016. 


\section{HESSD}

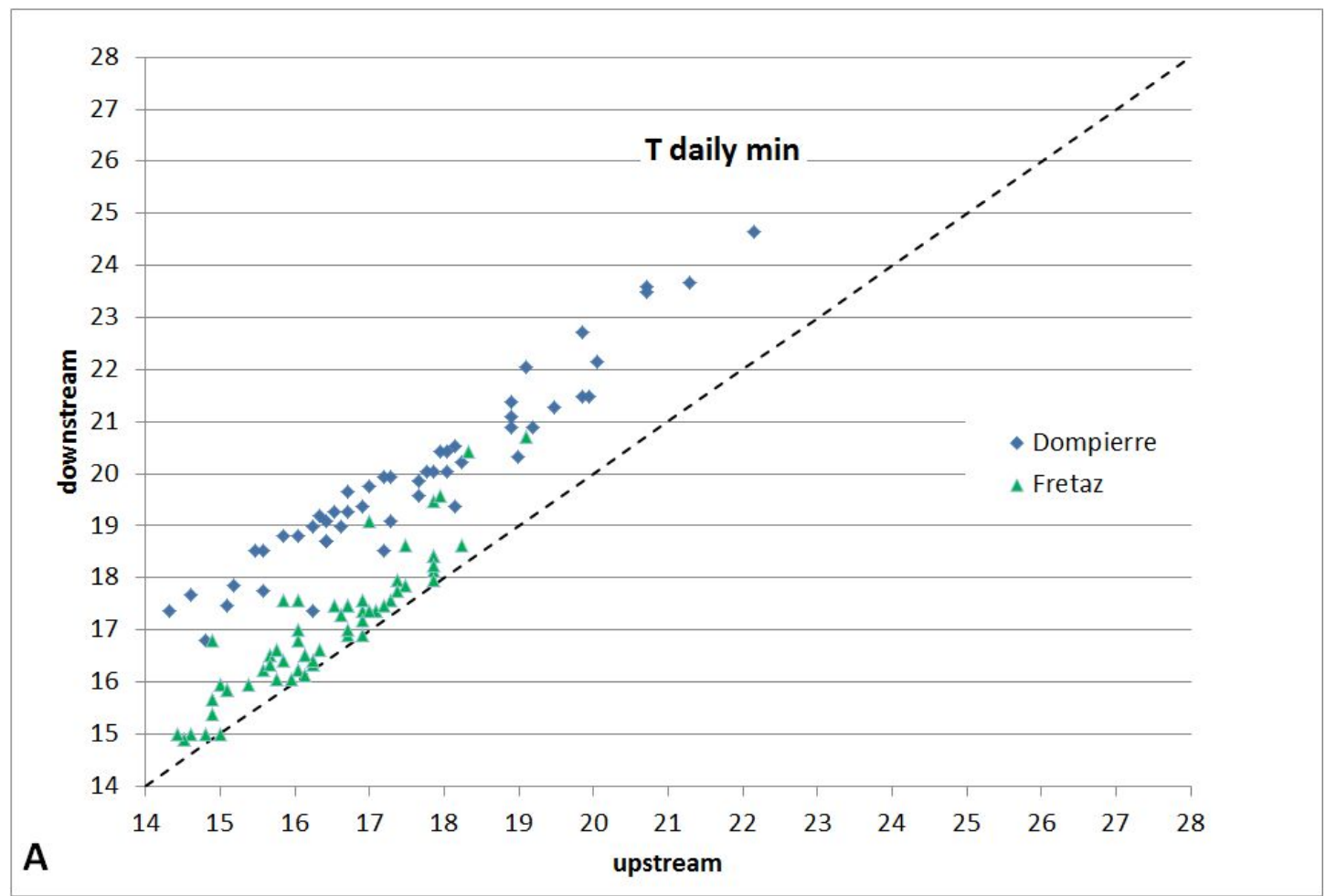

Fig. 6. Figure 4. Minimum (A) and maximum (B) daily temperatures upstream and downstream of the dams-of-the river (Dompierre site, Veyle stream in 2010; Fretaz site, Veyle stream in 2014). Dashed line is $1: 1$

\section{Interactive \\ comment}




\section{HESSD}

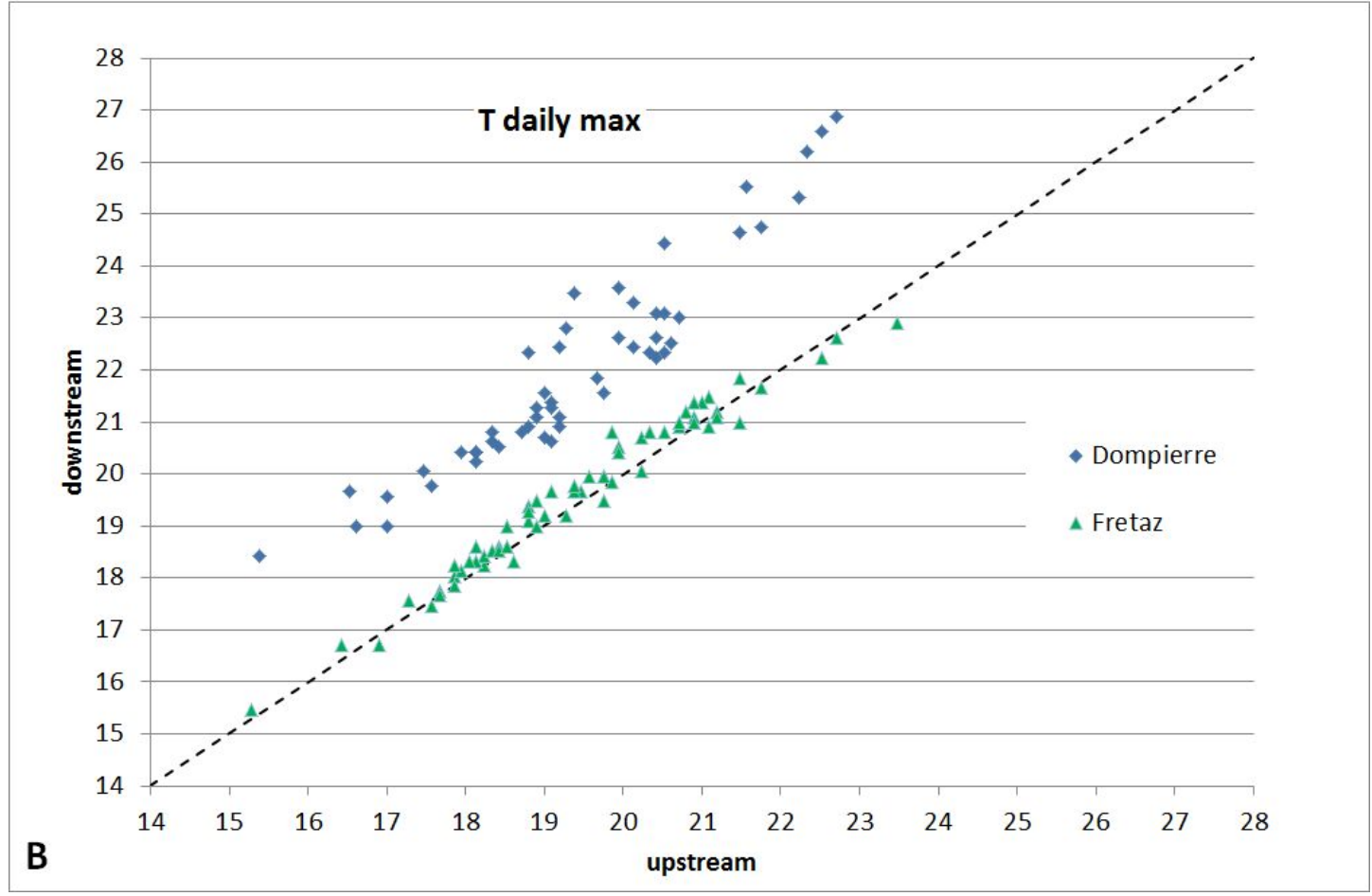

Fig. 7. Figure 4. Minimum (A) and maximum (B) daily temperatures upstream and downstream of the dams-of-the river (Dompierre site, Veyle stream in 2010; Fretaz site, Veyle stream in 2014). Dashed line is $1: 1$

Interactive

comment 


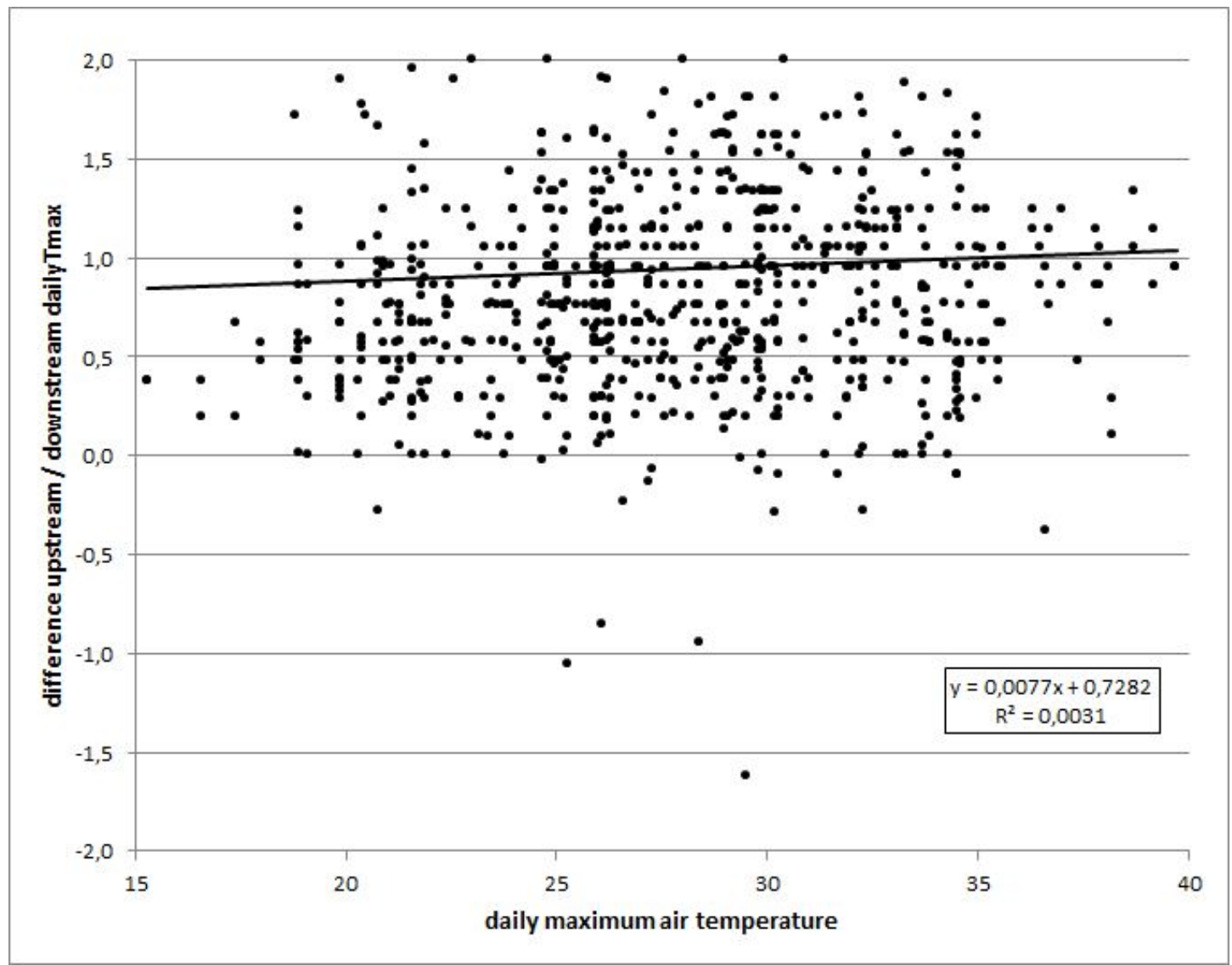

HESSD

Interactive

comment

Printer-friendly version

Fig. 8. Figure 5. Relation between daily maximum air temperatures $\left({ }^{\circ} \mathrm{C}\right)$, daily upstream/downstream temperature differences for all the data available for the study. 